\title{
A mudança técnica e o processo de diferenciação dos sistemas de produção pesqueira do Litoral do Paraná, Brasil
}

\section{Technical change and differentiation of small-scale fisheries production systems in the coast of Paraná, Brazil}

\author{
José Milton ANDRIGUETTO FILHO*
}

\section{RESUMO}

A pesca marítima do Paraná apresenta grande complexidade, composta por uma grande diversidade de ambientes aquáticos, uma variedade de práticas, em sua maior parte em regime de livre acesso, diferentes origens culturais dos pescadores, seus movimentos migratórios, níveis de inserção no mercado e usos de outros recursos naturais. Em meio a essa complexidade, seis sistemas de produção pesqueira foram reconhecidos em etapa anterior da pesquisa. O presente trabalho explora a hipótese de que aqueles sistemas estão relacionados por uma história evolutiva de diferenciação. Aplica-se uma abordagem interdisciplinar, concebendo-se os sistemas de produção como novos níveis de integração entre sistemas naturais e sociais. Dados sobre demografia, práticas e técnicas de pesca, comercialização da produção e outras fontes de renda e variáveis geográficas e ambientais foram obtidos em 1997, de várias fontes primárias e secundárias, incluindo entrevistas em 22 vilas e bairros pesqueiros. Os dados permitiram o desenvolvimento de um modelo evolutivo que descreve os padrões de diferenciação dos seis sistemas atuais. Estes têm um ancestral agro-pesqueiro no século XVIII e se diferenciam no século XX, quando a agricultura é desfavorecida. A diferenciação dos sistemas é causada principalmente pela evolução do mercado, dinâmicas demográficas, particularmente imigração, e inovação técnica, incluindo a invenção de novos equipamentos. Enquanto parte da pesca experimenta um processo de intensificação e maior inserção no mercado, alguns sistemas parecem em curso de desaparecimento. A gestão e a pesquisa não têm considerado as diferentes realidades da pesca paranaense, falhando, portanto, ao abordar problemas de meio ambiente e desenvolvimento.

Palavras-chave: pesca artesanal, pesca de pequena escala, sistemas técnicos, relações sociedade/natureza, mudança social, mudança técnica. 


\section{ABSTRACT}

Complexity of small-scale fisheries on the coast of Paraná is compounded by a great diversity of aquatic habitats, a variety of mostly open-access fishing practices, cultural origins of fishermen, their migratory movements, levels of market insertion, and uses of other natural resources. Amidst such complexity, six fishing production systems were described in a previous work. This work explores the hypothesis that they are related through an evolutionary history of differentiation. By conceiving production systems as new levels of integration between natural and social systems, the theory of nature/society interactions provides a comprehensive, interdisciplinary framework to explore relationships between natural, economic and social processes, hence to investigate environment and development issues. Data on demography, fishing practices and techniques, production marketing and other revenue sources, and geographical and environmental variables, were obtained in 1997 from various primary and secondary sources, including interviews in 22 fishing communities. An evolutionary model is developed to describe patterns of differentiation and factors of change of those systems. Present systems have common roots in the XVIII century, when agriculture and fisheries had both important roles in the economy. In the XX century, agriculture is abandoned, and system differentiation is mostly driven by market forces, demographic dynamics, particularly immigration, and technical innovation, including invention of new gear. While some systems show increased technology and market participation, others fail to cope with change, and seem to be bound to extinction. Management and research do not recognize such different realities, failing to address environment and development issues.

Key-words: small-scale fisheries, production systems, technical systems, nature/society interactions, social change, technical change.

\section{Introdução}

A pesca de pequena escala tem sido parte importante das atividades econômicas da zona costeira do Paraná há, pelo menos, dois séculos (MIGUEL, 1997). Andriguetto Filho et al. (1998) estimavam que mais de 10 mil pessoas, entre pescadores e suas famílias, habitassem, em 1996, as mais de 60 vilas ou bairros urbanos dos municípios de Antonina, Guaraqueçaba, Guaratuba, Matinhos, Pontal do Paraná e Paranaguá.

As pescarias marítimas paranaenses se caracterizam por grande complexidade social e ambiental, que propicia, ou pelo menos se expressa, numa notável multiplicidade de práticas e sistemas de pesca, com apetrechos e espécies-alvo diferentes, e de distribuição espacial heterogênea. No plano natural, o litoral se caracteriza por uma grande diversidade de habitas aquáticos, da plataforma costeira aos manguezais que circundam as baías. No plano social e cultural, a diversidade pode ser dada pela origem agrícola ou estritamente pesqueira dos atuais pescadores, pela procedência migratória e pelas influências culturais de origem externa, como a re- ligião. No plano das atividades econômicas, distinguemse diferentes graus de inserção no mercado e diferentes estratégias econômicas, com grupos ou vilas diferentes usando diferencialmente os recursos naturais (pesca, caça, agricultura e recursos florestais) ou dedicando-se aos empregos gerados pela urbanização (ANDRIGUETTO FILHO, 2002).

A complexidade e variedade de situações são em grande parte resultado de fortes pressões de mudança sofridas pela pesca, principalmente nas últimas décadas (ANDRIGUETTO FILHO et al., 1998; ANDRIGUETTO FILHO, 1999). A mudança social e particularmente a mudança técnica têm estado sujeitas a diversos fatores de pressão, como as mudanças no mercado, a evolução do turismo e da ocupação do solo e o endurecimento e complexificação da legislação ambiental. Além das normas de pesca, a atual proteção ambiental também dificulta ou impede o uso de muitos recursos florestais pelas comunidades pesqueiras. Trata-se de um tema delicado, pois o litoral paranaense abriga os últimos remanescentes da Floresta Ombrófila Densa na vertente Atlântica (a Mata Atlântica), sendo pontilhado por diversas unidades de conservação. Por outro lado, uma aparente redu- 
ção dos rendimentos pesqueiros, mudanças na composição das capturas e degradação de habitats resultaram em estratégias de adaptação dos pescadores, incluindo a invenção de novos apetrechos.

Nos últimos 10 a 15 anos, atenção crescente tem sido dada às pescarias paranaenses, pela necessidade de resolver seus problemas de desenvolvimento e, particularmente, de reduzir a pobreza (e.g., ROUGEULLE, 1989, 1993; SPVS, 1992; ATHAYDE; TOMAZ, 1995; CHAVES, 2002). No entanto, apesar de sua complexidade, as pescarias do Paraná têm sido consideradas, tanto pelo manejo como pela pesquisa, como um todo homogêneo, usualmente rotulado de "artesanal" ou, pior ainda, de "caiçara". Isto tem impedido, pelo menos em parte, um melhor conhecimento sobre as práticas materiais e as grandes dinâmicas sociais e ambientais da atividade, particularmente quando se trata das interações entre essas dinâmicas, frustrando os esforços de desenvolvimento.

Para lidar com a complexidade e melhor abordar as questões de desenvolvimento, o autor iniciou uma linha de pesquisa interdisciplinar, que tem como núcleo teórico a consideração das pescarias como sistemas técnicos e de produção complexos (ANDRIGUETTO FILHO, 1999, 2002). Nesta concepção, os sistemas de produção são uma grande interface ou novo nível de integração entre os sistemas natural e social (BLANC-PAMARD et al., 1992; CORMIER-SALEM, 1992; LALOË, REY; DURAND, 1995). Seguindo essa abordagem, trabalhos anteriores levaram ao reconhecimento da diversidade de situações pesqueiras (ANDRIGUETTO FILHO; MARCHIORO, 2002) e à determinação e descrição de seis diferentes sistemas de produção pesqueira no litoral do Paraná (figura 1) (ANDRIGUETTO FILHO, 2002). Neste último trabalho, examinaram-se hipóteses sobre as diferenças de identidade entre os sistemas. No presente artigo, serão examinados o processo de mudança técnica e os padrões de diferenciação dos sistemas ao longo do tempo.

O detalhamento das técnicas de pesca e características do recurso no Paraná pode ser encontrado na literatura (CORRÊA, 1987; CHAVES et al., 2002; NATIVIDADE et al., 2004 e ANDRIGUETTO Fil.ho et al., no prelo). No entanto, uma breve descrição dos sistemas é necessária. O sistema I é, na verdade, um sistema agropesqueiro, em que a agricultura é tão ou mais importante do que a pesca na economia da comunidade. Os aspectos propriamente pesqueiros do sistema são uma versão simplificada do sistema II. Este é o mais tradicional, ca- racterizado pela maior diversidade interna de práticas, desenvolvidas nas baías de Paranaguá e Guaratuba. Além da pesca de fundeio e deriva (ou caceio) para peixes, pratica-se a pesca de espinhel, uma variedade de cercos e pescas de "lanço" e a pesca do gerival ou tarrafinha, um tipo de rede de arrasto de travessão desenvolvido localmente. Este equipamento é amplamente utilizado na captura de camarão, pois não requer propulsão a motor e pode ser manejado mesmo por crianças. Moluscos, siri e caranguejo também são explorados. A embarcação mais comum é a canoa monóxila ("de um pau só”), usualmente a remo. Muitas das vilas neste sistema são remotas, inacessíveis por terra, o que torna o mercado fortemente dependente da intermediação. Nos sistemas III, IV e VI, as formas de pesca são praticamente restritas ao emalhe (fundeio e deriva) de peixes e camarão e ao arrasto de fundo de camarão. O sistema III é encontrado nas vilas rurais próximas às desembocaduras das baías, explorando-as tanto quanto ao mar aberto na plataforma interna próxima. Além das canoas, embarcações de tábua a motor, sem convés ou porão, são comuns. O sistema IV é o mais tecnificado e orientado ao mercado. Barcos de até 16 metros e 18 toneladas, equipados com motores de até $150 \mathrm{HP}$ e modernos equipamentos de comunicação e navegação, empreendem viagens de vários dias na plataforma interna. O processamento de pescado em terra também é desenvolvido, incluindo descascamento mecanizado de camarão, filetagem de peixe e congelamento. O sistema VI é caracterizado por vilas urbanas na costa sul e partilha com o sistema IV uma imigração e influência cultural intensa dos pescadores de Santa Catarina. Pode ser considerado intermediário entre os sistemas III e IV em termos de tecnologia e práticas de pesca. Finalmente, no sistema V, a pesca de arrastão de praia tradicional do Paraná, que tem na tainha seu principal alvo, está em declínio devido aos impactos sociais e econômicos da urbanização e do turismo.

\section{Metodologia}

Foram observadas 22 vilas ou bairros pesqueiros, em todos os municípios, à exceção de Morretes e Antonina. As vilas foram selecionadas de modo a abranger toda a variedade de situações técnicas, geográficas e sociais encontradas em etapas anteriores da pes- 

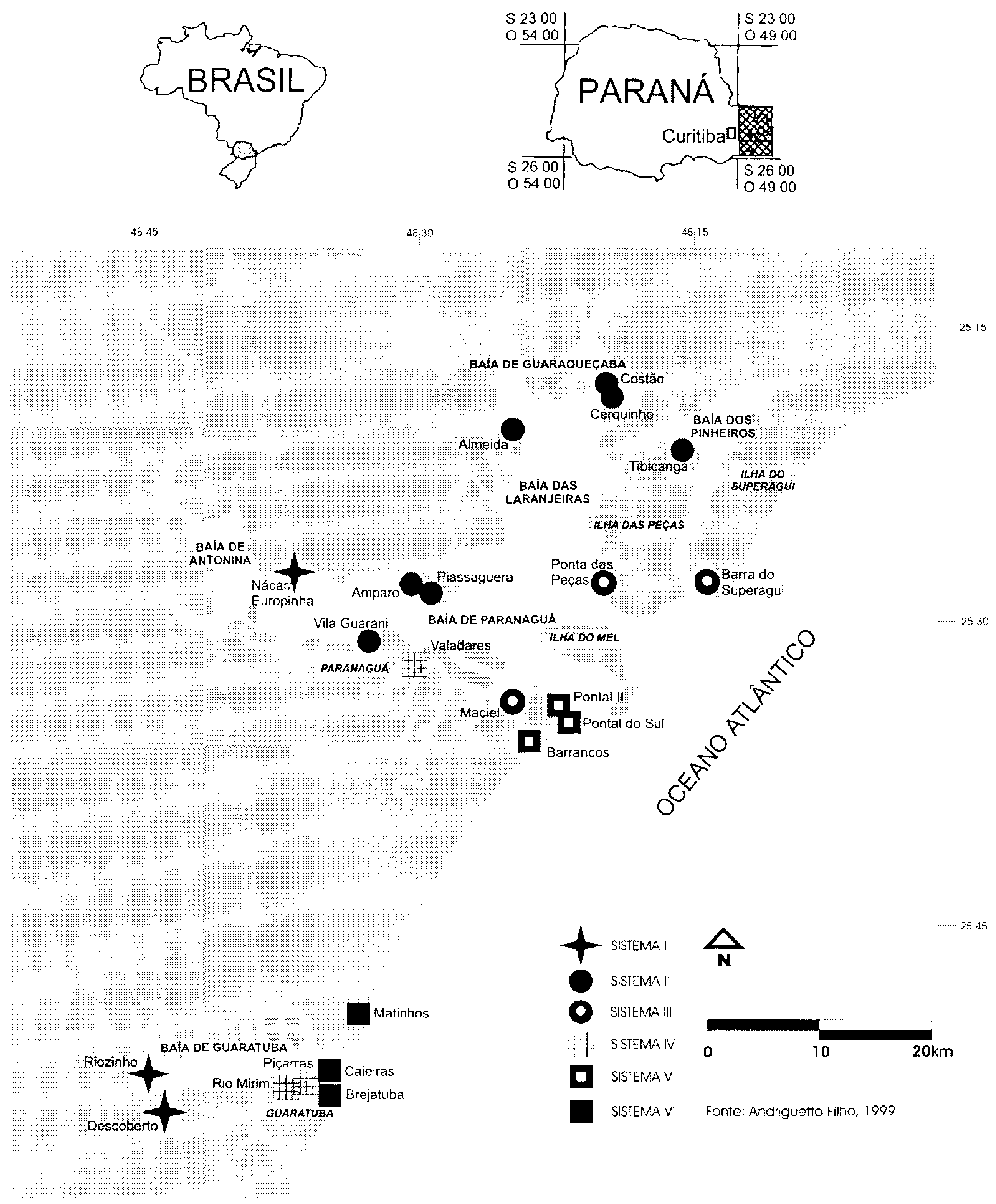
quisa (ANDRIGUETTO FILHO e MARCHIORO, 2002; ANDRIGUETTO FILHO et al. 2002) (tabela 1).

A informação foi obtida pela observação direta e aplicação de mais de 70 entrevistas livres a informantes privilegiados, em sua maioria pescadores mais velhos e/ou lideranças locais, no primeiro semestre de 1997. Esses informantes foram selecionados a partir de indicações dos próprios membros de cada vila, sugestões de responsáveis institucionais e professores da UFPR com experiência na região e principalmente a partir da participação do autor nas reuniões abertas para a discussão com os pescadores dos períodos de defeso para a pesca do camarão promovidas pelo Ibama e Emater em Paranaguá, Pontal do
Paraná e Guaratuba. As entrevistas foram agendadas previamente e gravadas com a anuência do entrevistado. Informação adicional e entrevistas foram obtidas com responsáveis institucionais no Ibama e Emater Paranaguá.

As entrevistas foram idealizadas e conduzidas de modo a fazer surgir particularidades da ocorrência e dos efeitos, em cada vila, das mudanças nas lógicas ou fatores de transformação. Além da informação objetiva recuperada diretamente, também se procurou pedir ou levar o entrevistado a apresentar a informação na forma de histórias de vida ou de crônicas de eventos. As entrevistas versaram sobre os componentes das dinâmicas sociais e naturais que pare-

TABELA 1 - VILAS EM QUE SE REALIZARAM ENTREVISTAS PARA ESTE TRABALHO. SISTEMAS PESQUEIROS RECONHECIDOS SEGUNDO ANDRIGUETO FILHO (2002).

\begin{tabular}{|c|c|c|}
\hline Sistema pesqueiro & Município & Vila ou bairro \\
\hline \multirow[t]{3}{*}{ T } & Paranaguá & Nácar/ Europinha \\
\hline & Guaratuba & Descoberto \\
\hline & & Riozinho \\
\hline \multirow[t]{7}{*}{ II } & Guaraqueçaba & Almeida \\
\hline & & Tibicanga \\
\hline & & Costão \\
\hline & & Cerquinho \\
\hline & Paranaguá & Vila Guarani \\
\hline & & Amparo \\
\hline & & Piassagüera \\
\hline \multirow[t]{3}{*}{ IIII } & Pontal do Paraná & Maciel \\
\hline & Guaraqueçaba & Ponta das Peças \\
\hline & & Barra do Superagüí \\
\hline \multirow[t]{3}{*}{ IV } & Paranaguá & Valadares \\
\hline & Guaratuba & Piçarras \\
\hline & & Rio Mirim \\
\hline \multirow[t]{3}{*}{$\mathbf{V}$} & Pontal do Paraná & Barrancos \\
\hline & & Pontal do Sul \\
\hline & & Pontal II \\
\hline \multirow[t]{3}{*}{ VI } & Matinhos & Matinhos \\
\hline & Guaratuba & Brejatuba \\
\hline & & Caieiras \\
\hline
\end{tabular}


ceram mais relevantes, tal como definidos pela fase anterior da pesquisa, com ênfase sobre a organização técnica e humana, no presente e no passado. O conteúdo foi compilado em grupos de variáveis mais específicas, que compreenderam, além de um sumário da história pessoal do entrevistado:

a) técnicas e estratégias de pesca: espaços de trabalho e portuário, apetrechos e modalidades de pesca, principais recursos e calendário de pesca, organização do trabalho e partilha da produção, perfil individual de apetrechamento e situação institucional (Ibama, Colônia de Pescadores e Capitania dos Portos);

b) processamento e comercialização da produção: infra-estrutura e canais imediatos de escoamento, indicativos de rendimento e problemas associados;

c) questões demográficas: tamanho atual e crescimento da vila, movimentos migratórios mais recentes, seu destino e procedência;

d) atividades produtivas: outras fontes de renda que não a pesca, alternativas de trabalho; presença de agricultura, de renda ou de consumo; presença do turismo;

e) uso do solo e questões fundiárias: história da urbanização, formas de domínio da terra, problemas e conflitos fundiários, incidência da legislação de proteção ambiental.

Como descrito por Andriguetto Filho (1999; 2002), a informação foi utilizada para estabelecer uma tipologia sincrônica de seis sistemas pesqueiros na região de estudo, agrupando as 22 vilas. A análise histórica da mesma informação neste trabalho permitiu a construção de um modelo evolutivo para descrever os padrões de diferenciação dos sistemas pesqueiros. O procedimento foi apoiado e validado por análise cladística, uma metodologia adaptada da biologia evolutiva e empregada neste contex to como um método lógico-matemático de ordenamento de entidades, a saber, as vilas e sistemas pesqueiros, ao longo de um eixo evolutivo. Como a resolução manual da matriz de entrada não era possível, a análise foi executada pelo programa Hennig86. Para uma descrição detalhada da análise cladística e sua discussão metodológica, veja-se Andriguetto Filho (1999 e no prelo).

\section{A diferenciação dos tipos de sistemas pesqueiros}

\section{O contexto histórico}

Em contraste com a situação atual, o litoral foi a região de maior dinamismo econômico do estado até pelo menos o início do século XIX. A região foi a primeira a ser colonizada, o que aconteceu ao longo do século XVII em função da exploração aurífera. Segundo Miguel (1997), desde o esgotamento do período de exploração do ouro ao início do século XVIII, estrutura-se um sistema agrário, pelo menos no litoral norte, inicialmente voltado à produção de autoconsumo e, em menor grau, ao abastecimento de um mercado local. Naquele período, a economia se reorganiza em torno da agricultura e do extrativismo florestal e pesqueiro. Com o surgimento dos primeiros agricultores-pescadores, entre índios e portugueses, estabelecem-se as raízes culturais da sociedade pesqueira marítima paranaense (ALVAR; ALVAR, 1979; IPARDES, 1989; ROUGEULLE, 1993).

Ainda no século XVIII, peixe seco era um dos principais produtos de exportação pelo Porto de Paranaguá, ao lado da farinha de mandioca e cordas e cabos de cipó e fibras naturais. Ao fim daquele século, o litoral ganha vantagens competitivas na produção de café, arroz e açúcar, e, já ao começo do século XIX, na transformação e exportação da erva-mate. $O$ advento da indústria do mate marca o início de um período de grande prosperidade econômica, em que crescem também as exportações de arroz, farinha de mandioca e madeira, todos produtos locais. Até pelo menos os meados do século XIX, a pesca era uma atividade importante e difundida e destinavase tanto ao autoconsumo quanto à venda. Ainda de acordo com Miguel (1997), as regiões de planalto do Paraná começam a suplantar o litoral, econômica e demograficamente já ao início do século XIX e, na segunda metade do século, a produção agrícola regional entra em crise, em função da abolição da escravatura e do forte aumento da concorrência em outras regiões do país e do mundo. A partir da metade do século XIX o litoral se reduz a simples zona de trânsito, especialmente com o deslocamento do beneficiamento do mate para o planalto. Diminui a atividade econômica e se retrai o mercado regional. Essa conjuntura acaba favorecendo a pesca, que permanece como alternativa à agricultura, até 
mesmo para os agricultores escravagistas. No mesmo contexto, inicia-se a produção de banana para exportação, particularmente para os países do Prata. Isto permite uma nova reorganização dos sistemas de produção, com base na agricultura de queimada, sendo banana, mandioca e arroz as culturas principais. No litoral norte, o período entre o fim do século XIX e os anos 30 do século XX é de um "crescimento econômico sem precedentes"; a população da região dobra entre 1890 e 1910.

A partir da década de 30 , o sistema de cultura de queimadas entra em crise, também em função da perda de competitividade e em função da opção pelo planalto nas iniciativas de desenvolvimento. Com a decadência econômica que se segue, a agricultura do litoral inicialmente se volta quase que exclusivamente ao mercado local ou à subsistência, e a pesca, além de servir à subsistência, começa a ganhar importância como fonte de renda, destinando-se cada vez mais ao mercado regional (Paranaguá e Curitiba). Além disso, intensifica-se o êxodo rural de pequenos agricultores e sua migração para as vilas ribeirinhas aos estuários e para os centros portuários. Esse movimento coincide com a melhoria das condições de conservação em gelo no Paraná, e com um aumento da demanda (MIGUEL, 1997). Na época, barcos de comerciantes do litoral paulista, providos de "geladeiras" (caixas com blocos de gelo), percorriam a Baía de Paranaguá para comprar a produção local. Da mesma forma, Antonina e Paranaguá estavam em pleno crescimento econômico com o desenvolvimento das atividades portuárias e comerciais. Mais tarde, a partir dos anos 60 e intensificando-se na década seguinte, implantar-seiam os grandes projetos agropecuários na região, para exploração madeireira, de palmito e criação de búfalos. Sem compromisso real com o desenvolvimento econômico ou social regional, tais atividades são determinantes no estabelecimento ou aprofundamento dos conflitos e heterogeneidades do litoral e dão novo ímpeto ao êxodo rural.

Intensificação da ocupação territorial, grilagem da terra e baixa fertilidade do solo fazem recrudescer, a partir de 1950, o desaparecimento da atividade agrícola em comunidades estuarinas e a migração de agricultores do interior para as comunidades ribeirinhas, para se tornarem pescadores. Das 22 vilas observadas neste estudo, em cinco nunca houve agricultura e em seis a agricultura desapareceu nas últimas décadas do século XX. Dos onze casos em que permanece, em seis deixou de ser de renda. Em outras três vilas, a agricultura de renda é praticada por muito poucos pescadores. Comprova-se o fenômeno de transição da agricultura para a pesca registrado na literatura e que ainda estava em curso em várias vilas até pelo menos a década de 90: Tibicanga (WINTHER et al., 1990); Barra do Superagüí (IPARDES, 1989), Tromomó e Costão (ROUGEulle, 1989; 1993), Ilha Rasa (SPVS, 1995). Tal processo representa uma segunda origem, exclusivamente agrícola e mais recente, dos atuais pescadores paranaenses. Finalmente, completando a formação da sociedade pesqueira marítima do Paraná, instala-se, a partir dos anos 60 do século XX, um fluxo quase contínuo de pescadores imigrantes de Santa Catarina para as vilas e bairros da orla oceânica, notadamente Caieiras, Piçarras, Matinhos, Pontal do Sul e Barra do Superaguii.

\section{A introdução das tecnologias e práticas recentes}

Antes de examinar a diferenciação dos sistemas é útil ter em mente a história da introdução das tecnologias atuais e de novas práticas na pesca paranaense. Embora pouco se conheça sobre o assunto, os principais marcos foram identificados a partir deste estudo e da literatura (SPVS, 1992 e 1995, ROUGEULLE, 1993).

O período que vai aproximadamente de 1965 a 1975 foi marcado pela introdução, em grande parte pela ação governamental, de um "pacote tecnológico" de intensificação da pesca composto pelos motores de centro, as fibras sintéticas e as embarcações ditas "de tábua". O evento que inaugura o "avanço tecnológico" é a introdução dos motores de pesca já no início do anos 60, e a aceleração de sua difusão nos anos 70 . Talvez seja a inovação de maiores consequiências, pois possibilita um grande aumento do alcance, capacidade e poder de pesca da frota, além do surgimento de novas formas de pesca. É o advento do motor que permite a introdução da pesca de arrasto de camarão, a forma mais produtiva e generalizada de pesca no Paraná, bem como do cerco de sardinha.

A introdução das fibras sintéticas acontece ao final dos anos 60 e início dos 70. A nova tecnologia aumenta a durabilidade das redes, facilita seu manuseio e diminui o tempo necessário à confecção e manutenção. Por outro lado, permitiu o aumento exagerado das redes de espera e, mais tarde, de deriva ou caceia, também formas dominantes de pesca atualmente. De panos tra- 
dicionais de 45 metros, as redes de hoje atingem até 2000 $\mathrm{m}$, com panos justapostos. Além do aumento quantitativo na capacidade e esforço de pesca, a prática passa também a assumir caráter intrinsecamente predatório quando as redes são confeccionadas com malhas muito pequenas ou utilizadas de modo a bloquear canais.

As embarcações "de tábua" vêm substituir a canoa "de um pau só" no início dos anos 70. Os diversos tipos parecem surgir quase que simultaneamente, embora os barcos, maiores, tenham levado mais tempo para se difundir, em função do custo ${ }^{1}$. Como os motores, as novas embarcações representam maior capacidade de transporte, e de alcance e poder de pesca, principalmente para a pesca de arrasto de camarão. Enquanto uma canoa tem capacidade para apenas algumas centenas de quilos de pescado, devendo retornar ao porto diariamente, os maiores barcos com porto no Estado têm autonomia de várias semanas e capacidade de até 18 toneladas. Outra vantagem da embarcação de tábua é a facilidade de reparo em relação à canoa, pois se trata apenas de substituir a seção danificada.

De aparição também nos anos 70 , a possibilidade de congelamento traz implicações notórias para todo o sistema de produção. O congelamento aumenta a qualidade do pescado e diminui as perdas, implicando aumento do rendimento financeiro. Embora não haja análises sobre os impactos desta tecnologia na pesca paranaense, é válido supor que dentre estes se encontrem um aumento de demanda, a partir do acesso a novos mercados, principalmente daqueles mais afastados. É preciso considerar que a tecnologia do frio pressupõe a existência de eletrificação, o que não acontece, ou só veio a acontecer recentemente, em várias vilas dos sistemas I, II e III no litoral do Paraná.

É importante notar que todas estas novas tecnologias foram utilizadas antes em Santa Catarina. Elas se difundem para o Paraná seja por observação do que se faz em Santa Catarina, seja pela imigração do pescador catarinense. A tabela 2 mostra a presença das diversas tecnologias mencionadas segundo o tipo de sistema de produção, corroborando a tipificação destes e o gradiente tecnológico da baía para o mar, apresentados em Andriguetto Filho (2002). O sistema I corresponde ao sistema técnico mais rudimentar, enquanto os sistemas IV e VI, de pesca em mar aberto e urbanos, apresentam a maior tecnificação, com a presença da pesca de barcos emIV.

Além das novas tecnologias, algumas modalidades de pesca são ou parecem ser recentes no Litoral. Talvez o arrastãozinho ou gerival seja uma das mais notáveis, uma vez que seu advento não dependeu de nenhuma tecnologia nova, mas apenas da criatividade local. Este apetrecho parece ter sido inventado em 1980 ou 1981, na região da Baía de Paranaguá, tendo possibilitado a "corrida" à pesca do camarão como alternativa de renda (ANDRIGUETTO FILHO, 1999). Outro exemplo notável de modificação técnica é a introdução dos tubos de PVC na fabricação dos cercos fixos, originalmente e ainda em sua maior parte confeccionados de taquara. Como o PVC é um material caro, infere-se que os cercos são compensadores financeiramente, como de fato evidenciado por Dias (1990). Finalmente, a pesca do irico parece ser de aparição historicamente recente, estimulada por demandas aparentemente altas do mercado paulista e internacional.

\section{A diferenciação dos tipos paranaenses}

Estabelecer ligações históricas e procurar relações de tipo evolutivo entre os tipos de sistemas é particularmente importante na investigação dos fatores da diferenciação. Para tanto, os elementos temporais ou históricos da informação disponível foram organizados em um modelo, em parte especulativo, sobre aquelas relações. Postula-se que as vilas de pescadores atuais (e portanto os tipos de sistemas pesqueiros) teriam se diferenciado a partir de uma situação relativamente homogênea, constituída pelas vilas agro-pesqueiras historicamente instaladas no Litoral do Paraná até o final do século XIX, como descrito na literatura (SCHERER, 1988; ROUGEULLE, 1993; MIGUEL, 1997). A partir daí, é possível reconhecer eixos evolutivos ao longo dos quais pode ter havido a diferenciação dos tipos de sistemas, como demonstrado esquematicamente na figura 2 . Neste diagrama, procura-se destacar as situações que poderiam ser as testemunhas hoje das etapas da diferenciação.

Parece seguro postular que as vilas pesqueiras "originais" não seriam urbanas, que nelas se praticaria a agricultura, e que o nível tecnológico pesqueiro deveria

1 As embarcaçōes de tábua mais comuns no Paraná são os botes, baleeiras e barcos. Descrições dos tipos de embarcações e sua nomenclatura podem ser encontradas em Andriguetto Filho (1999), Chaves et al. (2002) e Andriguetto Filho et al. (no prelo). 
dicionais de 45 metros, as redes de hoje atingem até 2000 $\mathrm{m}$, com panos justapostos. Além do aumento quantitativo na capacidade e esforço de pesca, a prática passa também a assumir caráter intrinsecamente predatório quando as redes são confeccionadas com malhas muito pequenas ou utilizadas de modo a bloquear canais.

As embarcações "de tábua" vêm substituir a canoa "de um pau só" no início dos anos 70. Os diversos tipos parecem surgir quase que simultaneamente, embora os barcos, maiores, tenham levado mais tempo para se difundir, em função do custo'. Como os motores, as novas embarcações representam maior capacidade de transporte, e de alcance e poder de pesca, principalmente para a pesca de arrasto de camarão. Enquanto uma canoa tem capacidade para apenas algumas centenas de quilos de pescado, devendo retornar ao porto diariamente, os maiores barcos com porto no Estado têm autonomia de várias semanas e capacidade de até 18 toneladas. Outra vantagem da embarcação de tábua é a facilidade de reparo em relação à canoa, pois se trata apenas de substituir a seção danificada.

De aparição também nos anos 70 , a possibilidade de congelamento traz implicações notórias para todo o sistema de produção. O congelamento aumenta a qualidade do pescado e diminui as perdas, implicando aumento do rendimento financeiro. Embora não haja análises sobre os impactos desta tecnologia na pesca paranaense, é válido supor que dentre estes se encontrem um aumento de demanda, a partir do acesso a novos mercados, principalmente daqueles mais afastados. É preciso considerar que a tecnologia do frio pressupõe a existência de eletrificação, o que não acontece, ou só veio a acontecer recentemente, em várias vilas dos sistemas I, II e III no litoral do Paraná.

É importante notar que todas estas novas tecnologias foram utilizadas antes em Santa Catarina. Elas se difundem para o Paraná seja por observação do que se faz em Santa Catarina, seja pela imigração do pescador catarinense. A tabela 2 mostra a presença das diversas tecnologias mencionadas segundo o tipo de sistema de produção, corroborando a tipificação destes e o gradiente tecnológico da baía para o mar, apresentados em Andriguetto Filho (2002). O sistema I corresponde ao sistema técnico mais rudimentar, enquanto os sistemas IV e VI, de pesca em mar aberto e urbanos, apresentam a maior tecnificação, com a presença da pesca de barcos emIV.

Além das novas tecnologias, algumas modalidades de pesca são ou parecem ser recentes no Litoral. Talvez o arrastãozinho ou gerival seja uma das mais notáveis, uma vez que seu advento não dependeu de nenhuma tecnologia nova, mas apenas da criatividade local. Este apetrecho parece ter sido inventado em 1980 ou 1981, na região da Baía de Paranaguá, tendo possibilitado a "corrida" à pesca do camarão como alternativa de renda (ANDRIGUETTO FILHO, 1999). Outro exemplo notável de modificação técnica é a introdução dos tubos de PVC na fabricação dos cercos fixos, originalmente e ainda em sua maior parte confeccionados de taquara. Como o PVC é um material caro, infere-se que os cercos são compensadores financeiramente, como de fato evidenciado por Dias (1990). Finalmente, a pesca do irico parece ser de aparição historicamente recente, estimulada por demandas aparentemente altas do mercado paulista e internacional.

\section{A diferenciação dos tipos paranaenses}

Estabelecer ligações históricas e procurar relações de tipo evolutivo entre os tipos de sistemas é particularmente importante na investigação dos fatores da diferenciação. Para tanto, os elementos temporais ou históricos da informação disponível foram organizados em um modelo, em parte especulativo, sobre aquelas relações. Postula-se que as vilas de pescadores atuais (e portanto os tipos de sistemas pesqueiros) teriam se diferenciado a partir de uma situação relativamente homogênea, constituída pelas vilas agro-pesqueiras historicamente instaladas no Litoral do Paraná até o final do século XIX, como descrito na literatura (SCHERER, 1988; ROUGEULLE, 1993; MIGUEL, 1997). A partir daí, é possível reconhecer eixos evolutivos ao longo dos quais pode ter havido a diferenciação dos tipos de sistemas, como demonstrado esquematicamente na figura 2. Neste diagrama, procura-se destacar as situações que poderiam ser as testemunhas hoje das etapas da diferenciação.

Parece seguro postular que as vilas pesqueiras "originais" não seriam urbanas, que nelas se praticaria a agricultura, e que o nível tecnológico pesqueiro deveria

1 As embarcações de tábua mais comuns no Paraná sāo os botes, baleeiras e barcos. Descriçōes dos tipos de embarcaçōes e sua nomenclatura podem ser encontradas em Andriguetto Filho (1999), Chaves et al. (2002) e Andriguetto Filho et al. (no prelo). 
TABELA 2 - PRESENÇA DAS TECNOLOGIAS RECENTES, SEGUNDO O SISTEMA DE PRODUÇÃO PESQUEIRA. CÉLULAS EM BRANCO INDICAM A AUSÊNCIA DE TECNOLOGIA NO SISTEMA; OS TONS DE CINZA INDICAM IMPORTÂNCIAS RELATIVAS DO USO DA TECNOLOGIA.

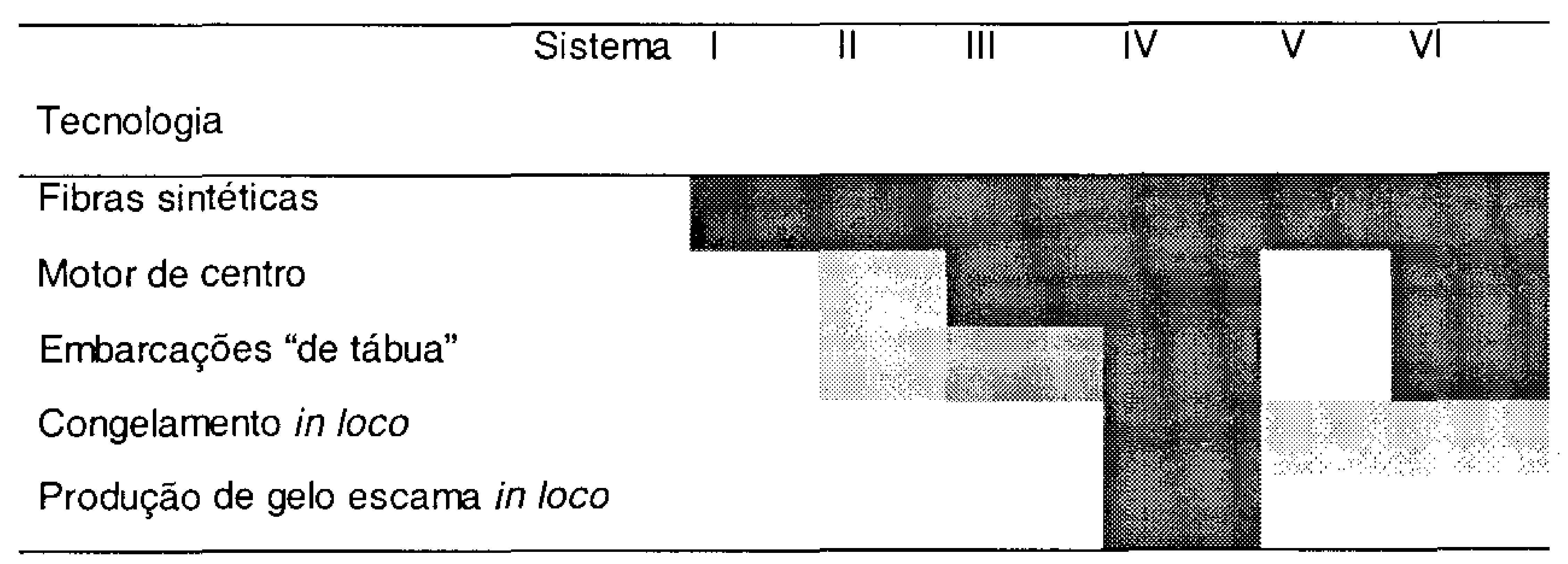

ser o menor entre os sistemas atuais. Isso restringe o ancestral ao sistema I, único em que a presença da agricultura mostrou consistência. Na figura 2 sugere-se que a vila de Nácar/Europinha pode representar a situação original, ou "ancestral hipotético", pois nesta vila a agricultura pareceu mais estruturada e importante do que em qualquer das outras vilas observadas. Agricultura e pesca são atividades econômicas importantes e praticadas pelas mesmas pessoas, dividindo o dia de trabalho. A rigor, em Nácar, é provável que a situação atual represente uma recuperação do caráter agro-pesqueiro, e não sua manutenção ao longo dos anos. Nesta vila, há pescadores exclusivos e agricultores-pescadores, mas parece não haver agricultores exclusivos.

A partir da situação original, as vilas do tipo I teriam evoluído no sentido do declínio da pesca e favorecimento da agricultura. Isso pode se dever a vários fatores, mas, sendo mais interioranas, a montante dos rios e nos fundos de baía, o potencial ambiental seria relativamente mais favorável à agricultura. Relatos em Piçarras e Nácar/Europinha, por exemplo, indicam atividade agrícola intensa, principalmente de produção de arroz, nas vilas da margem norte da baía de Guaratuba, e fundos das baías de Guaraqueçaba e Laranjeiras, há algumas décadas. A mercadoria era levada em canoa para os armazéns em Guaratuba e Paranaguá. Posteriormente, a agricultura também declina, por perder competitividade no mercado e pela ausência dos mecanismos de recuperação da atividade (como investimento e extensão rural). Em função da menor aptidão ambiental e da maior dificuldade de acesso ao mercado, a pesca não chega a se desenvolver novamente, favorecendo-se outras estratégias econômicas à medida que se apresentam a neces- sidade e a oportunidade. Riozinho e Descoberto representariam as vilas que seguiram esta evolução. Esta linha termina com uma possibilidade de extinção tendo em vista que estas vilas estão em situação geográfica semelhante e parecem ter perfil socioeconômico semelhante ao das diversas vilas cujo desaparecimento foi registrado por ANDRIGUETTO FiLHO (1999), ribeirinhas aos cursos baixos dos rios ao redor da Baía de Guaratuba e ao norte e oeste da Baía das Laranjeiras. Em particular, as formas de pressão fundiária observadas nas vilas do tipo I coincidem com o que se conhece para o litoral, particularmente para o município de Guaraqueçaba (ANDRIGUETTO FILHO e MARCHIORO, 2002). Neste caso, a extinção parece ocorrer por emigração para a cidade em busca de serviços e alternativas de renda.

As vilas do tipo II favoreceram a pesca estuarina, na modificação mais simples em relação à situação de origem. Com base na reconstituição histórica de Miguel (1997), apresentada anteriormente, é possível postular com segurança que o mercado está suficientemente desenvolvido para remunerar a pesca, e já não aceita mais o produto agrícola dessas vilas, que não poderia mais competir em qualidade e preço com os da agricultura tecnificada. A tecnologia adotada é a mais simples, em função do tipo de ambiente e de fatores como a ausência de eletricidade e a dificuldade de abastecimento (combustível, por exemplo). A falta de acesso ao capital pode ter também valor explicativo, mas trata-se de uma condição comum a todos os sistemas, pelo menos nalgum momento de sua história, e provavelmente com peso maior em tempos mais recentes. São estas as vilas (e as do tipo III) que receberam o êxodo rural ocasionado pela grilagem e/ou colapso da agricultura tradicional no continente, 
ou mesmo se formaram a partir dele, como é o caso das vilas na Ilha Rasa. A importância da pesca como atividade econômica aumenta nestas vilas, a maioria das quais abandona definitivamente a agricultura. Dentro deste tipo, Almeida e Tibicanga mostram menos influências do contato com o urbano, e parecem representar um momento evolutivo um pouco anterior às demais vilas do tipo.

As circunstâncias acima, de diferenciação precoce, condizem com o caráter de pesca artesanal tradicional reconhecido na literatura para as vilas do tipo II, e sugerem que esse era o tipo de pesca dominante nas baías paranaenses há algumas décadas. Assim, sua atual distribuição espacial, restrita a áreas mais internas da Baía de Paranaguá, deve ser remanescente de uma maior abrangência no passado. Permanece plausível a hipótese levantada por Andriguetto Filho e Marchioro (2002) de que esta pesca hoje se exerce em zonas de menor produtividade não como característica intrínseca, mas como uma situação residual, resultante tanto de fatores de ruptura quanto do menor nível de impactos ambientais na sua área de ocorrência, especialmente em Guaraqueçaba. De fato, algumas das técnicas deste sistema, particularmente o cerco fixo de taquaras, estão dentre as mais antigas do Paraná, com registros desde pelo menos o século XVIII (MIGUEL, 1997). Também se infere que este sistema de produção até o momento não representou impacto importante ao ecossistema aquático. Mas a informação disponível sugere que essa situação pode ser insustentável, pois os espaços em questão são áreas sensíveis importantes à proteção dos próprios recursos pesqueiros e neles têm crescido tanto a pressão pesqueira quanto os impactos de origem não-pesqueira.

O tipo III seguiria trajetória semelhante ao anterior, mas adaptando-se a uma pesca também marítima. A pressão fundiária para abandono da agricultura também foi um fator importante. Considerando a cronologia das inovações técnicas mais recentes, este grupo deve ter evoluído a partir do anterior. Neste caso, a partir do mesmo sistema técnico, e dada a sua posição geográfica permitindo o acesso ao mar, este grupo passa a se diferenciar do anterior ao assimilar ou poder fazer melhor uso dos novos elementos técnicos (principalmente o motor) que lhe permitem a pesca também no mar, enquanto o anterior permanecia restrito à baía.

Resumindo, a diferenciação dos grupos II e III a partir de I seria explicada por uma conjugação de três causas: uma evolução do mercado favorável à pesca e desfavorável à agricultura; a mudança técnica permitindo aumentos de produtividade, principalmente do grupo III, e o potencial ambiental diferenciado, dada pela localização geográfica.

Vilas dos tipos II e III podem evoluir para o tipo IV, quando se encontram próximas a centros urbanos, dos quais acabam se transformando em bairros não-turísticos. Isso cria as condições para o surgimento da pesca empresarial (barcos camaroneiros) no Estado. Esta acontece por iniciativa de pescadores catarinenses, especialmente em Guaratuba, e exige a conjugação da evolução do mercado (inclusive de trabalho), da infraestrutura urbana, da inovação técnica e das condições fisiográficas. Estas são determinantes, pois os barcos exigem águas abrigadas, mas não distantes do mar. $\mathrm{O}$ mesmo conjunto de condições também favorece o recebimento dos fluxos migratórios de pescadores das vilas menos favorecidas "dos rios" ou "das ilhas". De fato, nestes bairros, convivem os sistemas técnicos de tipo III e IV. A transformação em bairro urbano faz desaparecer a estrutura espacial de vila pesqueira, pois as casas dos pescadores estão espalhadas em meio à malha urbana.

$\mathrm{O}$ tipo $\mathrm{V}$ parece representar um outro resultado possível dos processos que levam de III a IV. A pesca marinha é favorecida e o ambiente de costa aberta, sem porto, não atrai a pesca de barcos. Todavia, o produto final parece resultar menos do estado inicial do que da forma de ação dos fatores de mudança. A pressão fundiária urbana, agora sob a forma de especulação imobiliária turística, e a evolução do mercado de trabalho parecem ter provocado o progressivo abandono da atividade pesqueira. $\mathrm{O}$ mecanismo é duplo: ao contrário do tipo anterior, aqui a urbanização expulsa o pescador, enquanto o turismo cria diversas alternativas de renda fora da pesca (BORGES et al., 2004). Esta por sua vez torna-se intrinsecamente menos interessante se a queda nos rendimentos e os impactos sobre os estoques forem reais. $\mathrm{O}$ desaparecimento como comunidades pesqueiras, ou seja, da atividade da pesca, parece não estar distante no futuro.

A vila de Barrancos é a exceção que confirma a regra, pois parecia seguir a mesma trajetória das demais até conseguir garantir na justiça o seu espaço físico, o que parece ter sustado o declínio. A pesca aí se mantém viável como nas vilas do grupo VI. Mesmo assim, a maior parte dos membros da vila já não ganham mais a 
FIGURA 2 - RELAÇÕES EVOLUTIVAS ENTRE OS TIPOS DE SISTEMAS DE PRODUÇÃO PESQUEIRA DO LITORAL DO PARANÁ.

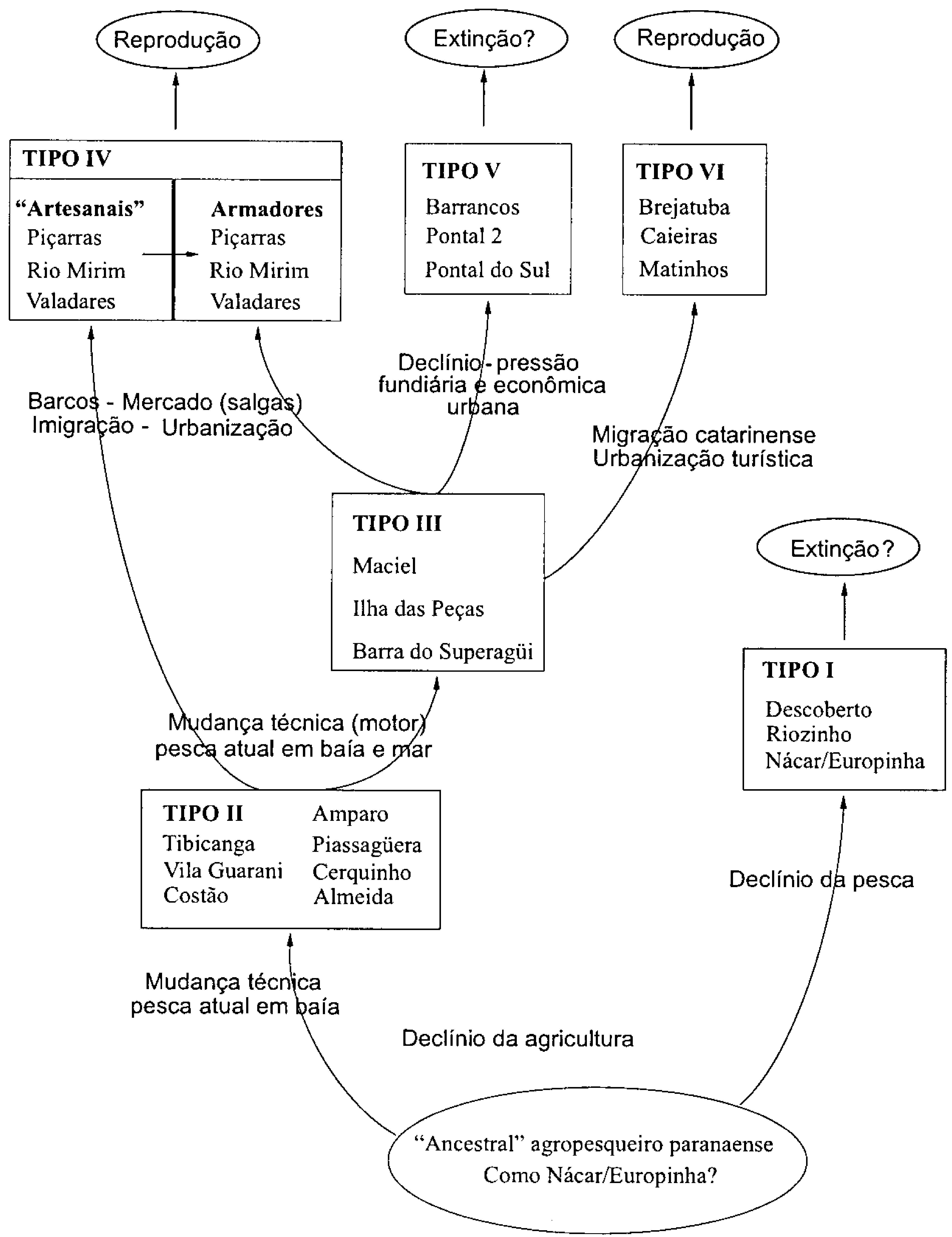


vida como pescadores, principalmente os mais jovens. De qualquer modo, ainda não há informações suficientes para explicar por que a pesca não compensa mais, ou fracassou como alternativa econômica nessas vilas, quando permanece nos tipos IV e VI.

O caso dos Pontais também é ilustrativo. A dinâmica que pareceu dominante neste estudo foi a do declínio da pesca tradicional paranaense, mas já existem alguns barcos camaroneiros de pescadores catarinenses, provenientes de Guaratuba, instalados no antigo cais de embarque para a Ilha do Mel. Por sua posição em entrada de baía e relativa facilidade de acesso terrestre para o escoamento da produção, era possível prever que a pesca de arrasto de camarão pelos catarinenses também se instalasse em Pontal. Esses pescadores estão ocupando terrenos bastante valorizados, dos quais geralmente detêm apenas a posse, o que representa um risco à continuidade do sistema. Mas, havendo porto adequado para abrigo das embarcações e desembarque da produção, a moradia junto ao mar é desnecessária, como acontece em Piçarras. Como há áreas de terra menos valorizadas em Pontal, o modelo proposto faz prever uma evolução semelhante à de Piçarras, com a expansão da pesca de barcos de Guaratuba para Pontal do Paraná. Caso isso se concretize, assistir-se-ia em Pontal a uma substituição da pesca tradicional paranaense por uma pesca mais tecnificada e comercialmente agressiva catarinense.

O tipo VI se diferencia de III a partir da adoção de uma pesca exclusivamente marinha e da migração de pescadores catarinenses para localidades pesqueiras paranaenses na orla oceânica. Embora as condições de escoamento da produção e acesso ao mercado sejam semelhantes às do tipo IV, a situação geográfica impediu a penetração das "salgas". e da pesca de barcos. O tipo de sistema técnico é o mesmo do sistema $\mathrm{V}$, do qual o sistema VI se distingue pela total ausência da agricultura, e porque nele não se verificou o forte abandono ou involução da pesca. Como nos limites estabelecidos neste trabalho, as demais condições foram as mesmas, a explicação para o sucesso relativo deste tipo pode estar na procedência catarinense, que deve implicar em diferenças sociais e/ou econômicas importantes.

É preciso considerar que a urbanização aconteceu antes nos tipos V e VI, e mais tarde no tipo IV, como sugerido pela análise cladística. De fato, no primeiro caso trata-se de uma urbanização iniciada nos anos 50 e 60, de classe média e alta, motivada pelo turismo, enquanto nas vilas do tipo IV o fenômeno é bem mais recente, ainda estar em curso, e ser motivado pela recepção dos emigrantes das zonas rurais do litoral. As vilas do tipo IV são áreas urbanas de baixa renda, à exceção da orla imediata da baía em Piçarras, hoje ocupada por casas de veraneio e marinas.

Em síntese, os principais fatores que se mostraram úteis para entender a diferenciação dos sistemas de produção da pesca marítima do Paraná foram:

- Potencial ambiental, diferencial ou não, para a agricultura e para a pesca, esta condicionada pelo ambiente natural (interior das baías, mar aberto ou os dois);

- Inovação tecnológica e momento em que acontece, permitindo o (maior) acesso ao mar e a diversificação e intensificação diferencial das atividades;

- Formas de pressão fundiária (rural ou urbana, intensidade, momento histórico em que acontecem);

- Evolução do mercado, diferencialmente para a pesca e agricultura, e da oferta de emprego;

- Influências migratórias posteriores, especialmente a imigração catarinense, mas também a turística e a migração campo-cidade.

Estes aspectos não esgotam a gama de dinâmicas por trás da mudança técnica. Na próxima seção, são abordados alguns processos de caráter mais geral, que não levam necessariamente à diferenciação dos sistemas, mas atuam de forma semelhante influenciando a mudança técnica em vários deles.

\section{As dinâmicas de transformação}

Um componente maior da mudança pesqueira no Paraná é a origem agrícola da maioria das famílias de pescadores, o que pode ter determinado algumas das características dos atuais sistemas de produção pesqueira. Na elaboração da tipologia (ANDRIGUETTO FILHO, 2002), verificaram-se algumas relações entre o papel da agricul- 
tura e a comercialização que parecem não ser casuais. As vilas com menos restrições à comercialização são aquelas onde se verifica o declínio da agricultura e ascensão da pesca. Isso condiz com a hipótese de que o acesso ao mercado e o aumento das facilidades para a comercialização da pesca estão associados ao declínio da agricultura, já deprimida pela perda de competitividade (MIGUEL, 1997). Por outro lado, todas as vilas "estritamente pesqueiras" têm atravessador local, menos Matinhos (onde, de qualquer forma, o Mercado não deixa de funcionar como um "atravessamento" local). Inversamente, nenhuma das quatro vilas sem atravessador local (excluindo Matinhos) é "estritamente pesqueira". Em todas houve declínio da agricultura. Isso sugere que o escoamento da produção pesqueira organizado por membros da própria vila seria característica das vilas tradicionalmente ou estritamente pesqueiras. É como se estas se organizassem para ir ao mercado vender seu produto, por oposição às agrícolas, onde o mercado (o atravessador externo) vem apresentar uma demanda à vila, que então troca de atividade da agricultura para a pesca. $O$ pescado acabou assumindo para estas vilas mais valor do que o produto agrícola, sendo um mercado em que podem competir (bom produto a bom preço), o que deixa de acontecer na agricultura, com o desenvolvimento desta no planalto (MIGUEL, op.cit.).

Outras heranças da agricultura estão relatadas na literatura. Rougeulle (1993) constata que, embora haja espaços coletivos preferenciais para o desembarque de pescado, também é comum o porto individual, de localização mais cômoda em relação à casa do pescador. Aquela autora avança a hipótese de que o porto individual poderia ser reflexo da herança de trabalho individual da agricultura. No presente trabalho, a mesma situação foi observada em todas as vilas visitadas. O porto foi individual sempre que possível, obedecendo a critérios de conveniência prática, e o tipo de porto não serviu para discriminar os sistemas técnicos. Rougeulle (op. cit.) sugere que também as formas e práticas de pesca individual, particularmente o gerival ou tarrafinha para a pesca do camarão, são favorecidas pela concepção de trabalho individual na agricultura. Ao contrário da anterior, esta hipótese não se sustenta diante da evidência obtida neste trabalho. As formas mais antigas de captura de camarão dentro da Baía de Paranaguá eram coletivas, a saber, o lanço em canoa, que exigia quatro homens, e a rede de "ástea" ou "hástea", que exigia dois.
Por outro lado, se as formas posteriores eram individuais, tudo indica que as razões para a adoção do gerival foram de ordem prática ou econômica. A pesca individual que antecedeu à do gerival foi a pesca "de engodo". $\mathrm{O}$ pescador precisava inicialmente preparar o engodo, ou isca, o que era feito fervendo-se peixes de menor valor, como sardinha e manjuba, e depois misturando com barro para formar as bolas de engodo. O material era então lançado nos pesqueiros, devendo-se esperar mais 20 a 30 minutos para que o camarão se concentrasse. Ao contrário do gerival, que pode ser usado em qualquer local, a pesca de engodo exigia águas rasas, sendo mais produtiva em maré cheia ou enchente e nos ambientes mais propícios ao camarão, que o pescador precisava conhecer. Também devia ser feita nos períodos de menor luminosidade, ou seja, do entardecer ao amanhecer. Para o ato de pescar em si, era preciso ficar em pé na canoa, e arremessar uma tarrafa de vários quilos, provavelmente várias dezenas de vezes em uma saída de pesca. O manuseio da tarrafa também implicava em logo ter as roupas e o corpo molhados. Em resumo, a pesca de engodo custava bastante tempo, exigia conhecimento do ambiente e da prática, exigia bastante esforço físico, implicava em desconforto, e a acessibilidade ao recurso era restrita no espaço e no tempo. Todos estes inconvenientes desaparecem ou se reduzem grandemente com o gerival. Adicionalmente, ao cobrir uma superfície maior, por ser uma prática de arrasto, o uso do gerival responderia à provável rarefação do recurso e diminuição dos rendimentos.

$\mathrm{O}$ advento do gerival permite considerar outra dinâmica subjacente à mudança técnica, que é a da maximização da renda. Na safra do camarão, a jornada de trabalho hoje vai das 6:00 às 18:00 horas. Em alguns depoimentos, pescadores mais velhos discordam da prática atual de pescar "nas duas marés", apontando que, com a pesca de engodo, pescava-se efetivamente apenas durante a maré noturna. Atualmente, quanto melhores as condições atmosféricas e maior o rendimento, tanto mais dias por semana e horas por dia se pesca, dentro ou fora da baía. Ou seja, enquanto a prática anterior embutia elementos de proteção ao recurso e limitava o esforço de pesca consideravelmente, hoje a regra é a maximização da captura, o que é acirrado pela penetração de não-pescadores na pesca de gerival, como assinalado por diversos autores (e.g., ATHAYDE E TOMAZ, 1995).

A via comum para o aumento dos rendimentos e da produção individual é o aumento da intensidade de 
pesca que, como se viu acima, é outra tendência de mudança geral entre os sistemas paranaenses. Se o declínio dos rendimentos e dos estoques, apontado pelos pescadores e parcialmente apoiado pelas estatísticas, é real, o estímulo para a intensificação é ainda maior. Outras trocas de apetrechos constatadas durante este estudo podem ser estratégias de resposta às mudanças nos recursos, para manter ou aumentar os rendimentos, mas a verificação disso exigiria estudos quantitativos. Observou-se, por exemplo, um consistente desfavorecimento do espinhel, que pode se dever a uma redução do tamanho individual e também da densidade das espécies de interesse. A pesca de caceio de malha de $5 \mathrm{~cm}$ (cinco centímetros) para o camarão branco na plataforma foi introduzida na década de 90 , por pescadores de arrasto de canoa ao longo da Praia de Leste (sistemas V e VI), em resposta à legislação do defeso, que só proibia a pesca de arrasto. Mas acabou sendo favorecida, pois se mostrou mais produtiva e de menor custo para o pescador de canoa. Em Caieiras, onde predomina a pesca de botes, a mesma mudança tardou um pouco, mas acabou acontecendo.

A intensificação não é a única reação dos pescadores à diminuição do recurso, havendo também respostas de gestão. A partir de meados da década de $80 \mathrm{o}$ arrasto de fundo e o cerco de sardinhas foram proibidos pela SUDEPE/IBAMA no interior das baías, por demanda do próprio setor pesqueiro, devido à queda de rendimentos que provocam em outras formas de pesca. O advento do motor e das novas modalidades de pesca, mudanças na técnica, levou a impactos negativos no ecossistema aquático, que se refletem numa queda do rendimento pesqueiro. Em resposta, os pescadores são os primeiros a demandar e apoiar a proibição daquelas práticas. O defeso do camarão é um caso semelhante. Inicialmente bastante combatida, a medida agora conta com o apoio da maior parte da classe pesqueira.

Finalmente, é preciso considerar que as transformações mais recentes estão associadas a um forte crescimento do contingente de pescadores. Andriguetto Filho et al. (no prelo) reportam que o número total de pescadores registrados junto ao IBAMA para todo o litoral sofreu um aumento importante, de mais de $39 \%$, de 4.702 para 6.548 , entre 1989 e 1996. Atualmente, o número total de pescadores do litoral com registro na SEAP-PR (Secretaria Especial da Aqüicultura e Pesca, regional Paraná) é da ordem de 4.200 , com os maiores contingen- tes em Guaratuba, Guaraqueçaba e Paranaguá. Este número é ainda provisório e deve aumentar em cerca de $30 \%$, à medida que pescadores com registro ainda válido junto ao IBAMA se recadastrem junto à SEAP. O valor também se aproxima do número total de pescadores em dia com as Colônias de Pesca.

\section{Elementos de conclusão}

Ao conjugar os resultados obtidos neste trabalho com aqueles de Andriguetto Filho e Marchioro (2002), chega-se à constatação de que há dois universos contrastantes de pesca de pequena escala: um rudimentar, pouco tecnificado e de baixa produção, outro diversificado, tecnificado e de maior produção. Estes dois universos parecem estar conectados por duas dinâmicas de transformação da pesca, concomitantes ou posteriores ao declínio da agricultura. De um lado, ocorre um aumento de desempenho e intensidade, em particular de um segmento do que aqueles autores chamam de "pesca artesanal diversificada", que experimenta um processo de complexificação, estando em transição para uma pesca mais comercial ou empresarial, cada vez mais inserida no mercado. De outro lado, uma parte da pesca artesanal parece sofrer um processo de marginalização, seja porque exercida por não-pescadores como complementação de renda, seja por causa da própria marginalização do pescador ao buscar outras atividades no meio urbano, e tendo a pesca também apenas como uma complementação de renda (BORGES et al., 2004).

Talvez uma percepção vaga destas dinâmicas esteja por trás de um dos mitos sobre a pesca artesanal brasileira, derrubados por Diegues (1988): o de que se trata de um setor de transição entre a pesca de autosubsistência e a pesca empresarial - capitalista e portanto tende a desaparecer. Como se vê, a questão é mais complexa. É a própria pesca artesanal ou de pequena escala que se transforma e diversifica. O caráter de transição definitivamente não é real, e no conjunto a atividade persiste, até porque, também negando um dos outros mitos apontados por Diegues (op.cit.), o pescador artesanal não é resistente às mudanças tecnológicas. Mas os riscos de desaparecimento de alguns sistemas são reais.

Considerando-se que a única pesca de entrada formalmente limitada no Paraná é a pesca de arrasto 
de camarão, a dinâmica de marginalização pode bem representar um exemplo clássico da "tragédia dos bens comuns" (HARDIN, 1984), ou mais precisamente, "do acesso livre" (WEBER e REVERET, 1993; WEBER, 1994), onde a tentativa de maximizar a produção individual só leva a uma queda geral de rendimento. O próprio pescador tradicional se vê obrigado a valerse de métodos que considera predatórios para maximizar seus rendimentos a curto prazo. Além dos efeitos sobre os recursos, essas dinâmicas parecem ter levado também a clivagens na sociedade de pescadores, como a evidenciada por uma representação constatada entre os pescadores tradicionais em relação à mudança técnica: os que pescam camarão com gerival ou caceio não são pescadores, mas caceadores (SPVS, 1992). Os que trabalham como quinhoeiros e aqueles que só possuem o gerival e a rede de caceio para camarão, pelo menos no interior das baías, são considerados desprovidos de apetrechos, inclusive por eles próprios.

Em conclusão, apesar da multiplicidade de fatores por trás da mudança técnica, parecem predominar aque-

\section{REFERENCIAS}

ALVAR, J.; ALVAR, J. Guaraqueçaba, Mar e Mato. 2. v. Curitiba: UFPR, 1979. 2. v. 207 p.

ANDRIGUETTO FILHO, J. M. Sistemas técnicos de pesca e suas dinâmicas de transformação no Litoral do Paraná, Brasil. Curitiba, 1999. 254 p. + anexos. Tese (Doutorado) - Universidade Federal do Paraná e Université de Bordeaux II.

ANDRIGUETTO FILHO, J. M. Sistemas técnicos de pesca no litoral do Paraná: caracterização e tipificação. In: RAYNAUT, C. et al. (Ed.). Desenvolvimento e Meio Ambiente - em busca da interdisciplinaridade. Curitiba: Ed. UFPR, 2002. cap. 4 , p. 213-233.

ANDRIGUETTO FILHO, J. M. Determination of small-scale fisheries production systems and dynamics of their differentiation on the coast of Paraná, Southern Brazil, through cladistic analysis. In: WORLD FISHERIES CONGRESS, May 2004. Proceedings... Vancouver: University of British Columbia. No prelo.

ANDRIGUETTO FILHO, J. M.; TORRES, R. F.; TOMAZ, L. M. Interações, fatores de mudança e sustentabilidade das práticas materiais e dinâmicas ambientais nos sistemas técnicos da pesca artesanal. In: LIMA, R. E.; NEGRELLE, R. R. B. les de tipo econômico. A estrutura e condições de acesso ao mercado favorecem a pesca em detrimento da agricultura e estimulam a intensificação para a maioria dos sistemas, em especial a pesca de barcos. As oportunidades de trabalho no Litoral desencadeiam estratégias oportunistas de entrada de não pescadores na pesca e abandono da pesca pelos pescadores tradicionais, ou pelo menos pelos mais jovens. Este efeito é generalizado, mas tem função importante no declínio da pesca nos sistemas I, II e V. Finalmente, o acesso ao capital determina o acesso aos meios de produção, o que pode ter sido marcante para a diferenciação dos tipos III, IV e VI. O fato é que alguns sistemas não têm sido capazes de administrar a mudança, e parecem fadados ao desaparecimento. A redução dos problemas de desenvolvimento associados exige que a diversidade e complexidade das dinâmicas da pesca paranaense passem a ser consideradas pela pesquisa e pela gestão.

(Coord.). Meio Ambiente e Desenvolvimento no Litoral do Paraná: diagnóstico. Curitiba: Ed. UFPR, 1998. p. 95-104.

ANDRIGUETTO FILHO, J. M.; MARCHIORO, N. P. X. Diagnóstico e problemática para a pesquisa. In: RAYNAUT, C. et al. (Eds.). Desenvolvimento e Meio Ambiente - em busca da interdisciplinaridade. Curitiba: Ed. UFPR, 2002. cap. 2, p. 159-194.

ANDRIGUETTO FILHO, J. M. et al. 2002. Metodologia de um diagnóstico preliminar. In: RAYNAUT, C. et al. (Ed.). Desenvolvimento e Meio Ambiente - em busca da interdisciplinaridade. Curitiba: Ed. UFPR, 2002. cap. 1, p. 139-157.

ANDRIGUETTO FILHO, J. M.; CHAVES, P. T.; SANTOS, C. e LIBERATI, S.A. Diagnóstico da pesca no estado do Paraná. Projeto RECOS - uso e apropriação dos recursos costeiros, componente Modelo Gerencial da Pesca, Institutos do Milênio. No prelo.

ATHAYDE, S. F.; TOMAZ, L. M. Áreas naturais protegidas e comunidades locais da Ilha do Mel-PR - Brasil. Nerítica, n. 9 , v. 1/2, p. 49-91, 1995. 
ANDRIGUETTO FILHO, J. M. A mudança técnica e o processo de diferenciação dos sistemas de produção...

BLANC-PAMARD, C.; DEFFONTAINES, J. P.; FRIEDBERG, C. Techniques et pratiques: à la jonction du naturel et du social. In: JOLLIVET, M. (Dir.). Sciences de la natures, sciences de la societé. Les passeurs de frontières. Paris: CNRS, 1992.590 p.

BORGES, L. M. M.; MAULIN, G. C.; ANDRIGUETTO FILHO, J. M. Analysis of Income Sources of Fishers' Families on the Coast of the State of Paraná, Brazil. Journal of Coastal Research, SI 39 (Proceedings of the 8th International Coastal Symposium), Itajaí, 2004.

CHAVES, P. T. A pesca artesanal na plataforma do Estado do Paraná entre a Baía de Guaratuba e o estuário do rio SaíGuaçu: uma abordagem ictiológica e social. Curitiba: Fundação Araucária, 2002. 48 p. Relatório final.

CHAVES, P. T, PICHLER, H.; ROBERT, M. Biological, technical and socioeconomic aspects of the fishing activity in a Brazilian estuary. Journal of Fish Biology, n. 61, p. 52-59, 2002. Suplemento A.

CORMIER-SALEM, M. C. Gestion et évolution des espaces aquatiques: la Casamance. Paris: Orstom, 1992. 583 p. (Collection Études et Thèses).

CORRÊA, M. F. M. Ictiofauna da Baía de Paranaguá e adjacências (Litoral do Estado do Paraná - Brasil). Levantamento e produtividade. Curitiba, 1987. 360 p. Dissertação (Mestrado) - Universidade Federal do Paraná.

Dias, E. R. A. Produtividade de um cerco fixo no Parque Estadual da Ilha do Cardoso, na região lagunar-estuarina de Cananéia. In: SIMPÓSIO DE ECOSSISTEMAS DA COSTA SULSUDESTE BRASILEIRA, 2., 1990, Águas de Lindóia. Anais... Águas de Lindóia, 1990. p. 400-408.

DIEGUES, A. C. S. Mitos e realidades sobre pescadores artesanais. Programa de Pesquisa e Conservação de Áreas Úmidas no Brasil. 1988. (Série Trabalhos e Estudos) 11 p. Mimeog.

HARDIN, G. The tragedy of the common. In: KORTEN,D. C.; KLAUSS, R. (Ed.). People Centered Development. Contributions toward Theory and Planning Frameworks. West Hartford: Kumarian, 1984. p. 84-96.

IPARDES. APA de Guaraqueçaba: caracterização sócio-econômica dos pescadores artesanais e pequenos produtores rurais. Secretaria de Estado do Planejamento e Coordenação Geral. Curitiba: Fundação Édison Vieira, 1989. 87 p.

LALOË, F.; REY, H.; DURAND, J. L. (Ed.). Questions sur la dynamique de l'exploitation halieutique. Avant-propos. Paris: Orstom, 1995. (Collection Colloques et Séminaires), p. 15-24.
MIGUEL, L. A. Formation, évolution et transformation d'un système agraire dans le sud du Brésil (littoral nord de l'État $d u$ Paraná). Une paysannerie face à une politique de protection de l'environnement: "Cronique d'une mort annoncée?". Paris, 1997. 313 p. + annexes. These (Doctorat) - Institut National Agronomique Paris-Grignon.

NATIVIDADE, C. D.; PEREIRA, M. J. C. F.; ANDRIGUETTO FILHO, J. M. Small-scale Fishing Landings on the Coast of the State of Paraná, Brazil - 1975-2000. Journal of Coastal Research, SI 39 (Proceedings of the 8th International Coastal Symposium), Itajaí, 2004.

ROUGEULLE, M. D. Pescas artesanais de Guaraqueçaba. In: DIEGUES, A. C. (Org.). Pesca artesanal: tradição e modernidade. In: ENCONTRO DE CIÊNCIAS SOCIAIS E O MAR, 3., 1989, São Paulo. Anais... São Paulo: Programa de Pesquisa e Conservação de Áreas Úmidas no Brasil, 1989. p. 281-288.

ROUGEULLE, M. D. La crise de la pèche artisanale: transformation de l'espace et destructuration de l'activité - le cas de Guaraqueçaba (Paraná, Brasil). Nantes, 1993. 410 p. These (Doctorat) - Université de Nantes.

SCHERER, E. Michaud, o pintor de Superagüí. Tradução: J. Graf. Curitiba: Imprensa Oficial, 1988. 104 p.

SPVS. Plano Integrado de Conservação para a Região de Guaraqueçaba, Paraná, Brasil. Curitiba: SPVS/TNC/Ibama, 1992. 2. v., 129 p.

SPVS. Vilas pesqueiras da APA de Guaraqueçaba: uma caracterização sociocultural. Projeto de co-gestão de manejo ambiental e desenvolvimento comunitário na APA de Guaraqueçaba, Paraná. Curitiba: Ibama/PNMA/SPVS, 1995. 57 p. Relatório de Pesquisa. Mimeog.

WEBER, J. Conservation, Appropriation et Processus de Décision dans le Cadre de la Conservation. Communication de Jacques Weber. Biodiversité: Le Fruit Convoité, p. 28-35, 1994. Dossier pour un débat. Fondation pour le Progress de l'Homme.

WEBER, J.; REVERET, J. P. La Gestión des Relations SocietésNature: Modes d'Appropriation et Droits de Proprieté. MS, 1993. 7 p.

WINTHER, J.; RODRIGUES, E. P. F.; MARICONDI, M. I. Laudo de ocupação da vila de Tibicanga - Ilha das Peças, Guaraqueçaba, Paraná. São Paulo: Instituto de Antropologia e Meio Ambiente (Iama), 1990. 